\title{
Tendências genética e fenotípica para ganho de peso médio diário entre a desmama e o sobreano em uma população Angus x Nelore
}

\author{
[Genetic and phenotypic trends for average daily weight gain from weaning \\ to 550 days of age in a Angus Nellore population] \\ D. D'avila Balbé ${ }^{1}$, P.R.N. Rorato ${ }^{2 *}$, J. Andreazza ${ }^{2}$, C.J. Kippert ${ }^{2}$, J.S. Lopes $^{2}$, \\ T. Weber $^{2}$, A.A. Boligon ${ }^{2}$, G.B. Ferreira ${ }^{2}$ \\ ${ }^{1}$ Aluno de pós-graduação - UFMS \\ ${ }^{2}$ Universidade Federal de Santa Maria \\ Campus Universitário de Camobi - Km 9 \\ 97119-900 - Santa Maria, RS
}

\begin{abstract}
RESUMO
Foram analisados os registros de ganho médio diário entre a desmama e o sobreano (GMDDS) de 33.267 animais de uma população multirracial Angus - Nelore, filhos de 525 touros, criados em 37 rebanhos, em diversas regiões do Brasil, entre os anos de 1987 e 2001. O modelo animal usado incluiu os efeitos aleatórios genético aditivo direto e materno e residual e os efeitos fixos de grupo genético do pai, da mãe e do animal e do grupo de contemporâneos pós-desmama, além da covariável idade à desmama, não ajustada. O GMDDS médio observado para a população foi 384,22g. O ano de 1999 foi o que apresentou o maior GMDDS (484,04g), e o ano de 1992, o menor $(299,42 \mathrm{~g})$. Os coeficientes de herdabilidade estimados foram: $0,30 \pm 0,11$ (direta) e $0,29 \pm 0,07$ (materna). O VG médio foi de $-0,827 \mathrm{~g}$. A tendência genética estimada para essa característica foi de $-0,029 \mathrm{~g} /$ ano $(\mathrm{P}<0,08)$ e a fenotípica foi de $5,69 \mathrm{~g} / \mathrm{ano}$ $(\mathrm{P}<0,05)$.
\end{abstract}

Palavras-chave: gado de corte, ganho de peso, herdabilidade, valor genético

\begin{abstract}
Direct and maternal heritability coefficients were estimated and genetic and phenotypic trends were predicted for average weight gain from weaning to 550 days of age (AWG) from 33,267 animals of a multi-breed Angus-Nellore population, sired by 525 bulls and raised in 37 herds in several regions of Brazil, from 1987 to 2001. MTDFREML was used for estimating the (co)variance components utilized to estimate the genetic direct and maternal heritability coefficients and to predict the breeding values. The animal model included as fixed the genetic group of sire, dam and animal and the pos weaning year/station/herd contemporary group and the covariate weaning age, and as ramdom, the additive genetic, maternal and residual effects. The observed AWG was $384.22 \mathrm{~g}, 1999$ presented the highest (484.04g) and 1992 the lowest value (299.42g). The direct heritability was $0.30 \pm 0.11$, the maternal $h^{2}$ was $0.29 \pm 0.07$ and the average genetic value was $-0.827 \mathrm{~g}$. The estimated genetic trend for AWG was $0.029 \mathrm{~g}(P<0.08)$ and the phenotypic trend was $5.68 \mathrm{~g}(P<0.05)$. A phenotypic progress for average weight gain from weaning to 550 days of age occurred as a consequence of an environmental improvement, and the estimated genetic progress was close to zero.
\end{abstract}

Keywords: beef cattle, weight gain, heritability, breeding value

Recebido em 23 de dezembro de 2004

Aceito em 16 de outubro de 2006

*Autor para correspondência (corresponding author)

E-mail: rorato@smail.ufsm.br 


\section{INTRODUÇÃO}

O cruzamento entre raças européias e zebuínas é utilizado para produzir animais com melhor desempenho nas condições brasileiras. De acordo com Alencar et al. (1995), é necessário identificar os cruzamentos que apresentem maior vigor híbrido e combinem características econômicas desejáveis para diferentes tipos de manejo e regiões do país, pois a superioridade dos animais cruzados em relação aos puros depende, principalmente, do ambiente que lhes é fornecido, das raças utilizadas e do valor genético dos indivíduos acasalados.

A implantação de um programa de melhoramento é um dos principais meios para se obter evolução genética para um rebanho, porém, uma vez implantado, é necessário que seja feita, periodicamente, a verificação de sua eficiência (Mello, 1999).

Uma forma de acompanhar o progresso genético alcançado pelo rebanho ao longo do tempo é avaliar a variação do ganho genético anual dos animais. Para avaliar esse progresso estima-se a tendência genética da população, quantificando o quanto da variação anual do rebanho tem origem genética. Para isso, é necessário que a mudança fenotípica seja decomposta nos seus componentes genéticos e de ambiente (Oliveira et al., 1995).

$\mathrm{Na}$ análise de experimentos de seleção com grande número de animais em que, normalmente, é impossível o controle das flutuações ambientais, uma complicação na estimação da resposta à seleção é, com certeza, a distinção entre as mudanças genéticas e ambientais (Walsh, 1999). Outro complicador é a variância considerável da resposta, em parte atribuída à deriva genética, uma vez que a seleção artificial envolve a escolha de pequeno número de pais para formar a próxima geração (Walsh, 1999). Falconer e Mackay (1996) ressaltaram, ainda, o problema da variabilidade das médias por geração (ou ano), as quais não avançam de maneira simples e regular, mas flutuam erraticamente e mais ou menos violentamente. A conseqüência disso é que a resposta raramente pode ser medida com acurácia até passar, pelo menos, as duas primeiras gerações de seleção.
Procedimentos de modelos mistos podem ser usados para analisar os dados, produzindo estimativas da variância genética e da resposta à seleção numa única análise (Sorensen e Kennedy, 1986). A metodologia de modelos mistos para o modelo animal incorpora a matriz das relações genéticas aditivas, levando em conta todas as covariâncias, tanto entre indivíduos dentro de uma geração como aquelas entre indivíduos de diferentes gerações, além de ponderar corretamente os indivíduos dessas famílias, usando registros da geração corrente e de todas as gerações passadas, para estimar a resposta à seleção e considerar $\mathrm{o}$ fato que algumas famílias fornecem mais informações. A omissão do relacionamento entre gerações tem implicações importantes na análise de dados gerados por seleção (Sorensen e Kennedy, 1984, 1986), pois experimentos de seleção são processos estocásticos e o desempenho em determinada geração depende da amostra genética retida na geração anterior (Hill, 1980).

O objetivo deste estudo foi avaliar as tendências genéticas e fenotípicas para ganho de peso médio diário entre a desmama e o sobreano de uma população multirracial Angus-Nelore, em diferentes regiões do Brasil.

\section{MATERIAL E MÉTODOS}

Foram utilizados registros de desempenho de 33.267 animais de uma população multirracial Angus(A)-Nelore(N), filhos de 525 touros $(1 \mathrm{~A}+0 \mathrm{~N}, 1 / 2 \mathrm{~A}+1 / 2 \mathrm{~N}, 5 / 8 \mathrm{~A}+3 / 8 \mathrm{~N}, 3 / 8 \mathrm{~A}+5 / 8 \mathrm{~N}$ e $0 \mathrm{~A}+1 \mathrm{~N})$ criados em 37 rebanhos, em diversas regiões do Brasil, entre os anos de 1987 e 2001.

O estudo foi realizado com informações fornecidas por Gensys Consultores Associados S/C Ltda. e Natura Genética Sul-Americana. Os dados foram estruturados de maneira a permitir a predição dos valores genéticos dos animais participantes do programa.

Foram geradas, usando o aplicativo SAS (User's...,1996), as seguintes variáveis: grupo contemporâneo, composto por animais nascidos no mesmo ano, estação e fazenda e pertencentes ao mesmo sexo e grupo de manejo; código de grupo genético, de acordo com a Tab. 1; ganho médio diário do desmame ao sobreano (GMDDS), sendo GMDDS = (PS - PD)/ $(\mathrm{IS}$ - 
ID), em que PS = peso ao sobreano $(\mathrm{kg}), \mathrm{PD}=$ peso à desmama $(\mathrm{kg})$, IS = idade ao sobreano (dias) e ID = idade à desmama (dias); estação de nascimento $1=$ animais nascidos nos meses de janeiro a março, 2 = nascidos de abril a junho, 3 $=$ nascidos de julho a setembro e $4=$ nascidos de outubro a dezembro.

Tabela 1. Relação dos grupos genéticos (contribuição das raças Angus-A e Nelore-N) e número de observações, para a população estudada

\begin{tabular}{ccc}
\hline $\begin{array}{c}\text { Grupo } \\
\text { genético }\end{array}$ & Contribuição & $\begin{array}{c}\text { Número de } \\
\text { observações }\end{array}$ \\
\hline 1 & $1 \mathrm{~A} \times 0 \mathrm{~N}$ & 5.860 \\
2 & $13 / 16 \mathrm{~A} \times 3 / 16 \mathrm{~N}$ & 802 \\
3 & $23 / 32 \mathrm{~A} \times 9 / 32 \mathrm{~N}$ & 224 \\
4 & $11 / 16 \mathrm{~A} \times 5 / 16 \mathrm{~N}$ & 3.481 \\
5 & $21 / 32 \mathrm{~A} \times 11 / 32 \mathrm{~N}$ & 2.263 \\
6 & $5 / 8 \mathrm{~A} \times 3 / 8 \mathrm{~N}$ & 5.432 \\
7 & $19 / 32 \mathrm{~A} \times 3 / 32 \mathrm{~N}$ & 563 \\
8 & $9 / 16 \mathrm{~A} \times 7 / 16 \mathrm{~N}$ & 4.655 \\
9 & $1 / 2 \mathrm{~A} \times 1 / 2 \mathrm{~N}$ & 9.883 \\
10 & $0 \mathrm{~A} \times 1 \mathrm{~N}$ & 104 \\
\hline
\end{tabular}

Os componentes de variância e covariância, utilizados para estimar as herdabilidades direta e materna e predizer os valores genéticos (VGs) foram obtidos pelo método da máxima verossimilhança restrita (REML), com o programa computacional multi traits derivative free restricted maximum likelihood (MTDFREML) de Boldman et al. (2001).

Para definir as variáveis a serem incluídas no modelo, foi realizada análise de variância utilizando o procedimento PROC GLM do pacote estatístico SAS (User's..., 1996), a qual revelou ser a característica GMDDS influenciada significativamente $(\mathrm{P}<0,001)$ pelas variáveis: idade à desmama; ano, estação e fazenda de nascimento; sexo e grupo de manejo, as quais foram incluídas no modelo para a análise genética.

Foi adotado um modelo animal que considerou o GMDDS em função dos efeitos aleatórios genéticos aditivos diretos e maternos e o residual e dos efeitos fixos de grupo genético do pai (5), da mãe (10), do animal (12) e do grupo de contemporâneos pós-desmama (animais nascidos no mesmo ano, estação e fazenda e pertencentes ao mesmo sexo e grupo de manejo), totalizando 752 grupos contemporâneos distintos, além da covariável idade do animal a desmama.
O modelo de análise utilizado é descrito como: y $=\mathrm{X} \beta+\mathrm{Z}_{1} \mathrm{a}+\mathrm{Z}_{2 \mathrm{~m}}+\mathrm{e}$, em que:

$\mathrm{y}=$ vetor das observações do caráter ganho de peso médio diário do desmame ao sobreano (GMDDS);

$\mathrm{X}=$ matriz de incidência associada aos efeitos fixos (grupo genético, grupo de contemporâneos pós-desmama e idade do animal a desmama); $\beta=$ vetor de soluções para os efeitos fixos de grupo genético, grupo de contemporâneos e a covariável idade do animal ao desmame;

$\mathrm{Z}_{1}=$ matriz de incidência associada aos efeitos genéticos aditivos diretos, aleatórios;

$\mathrm{Z}_{2}=$ matriz de incidência associada aos efeitos genéticos aditivos maternos, aleatórios;

$\mathrm{a}=$ vetor de efeitos genéticos aditivos diretos do animal, aleatórios;

$\mathrm{m}=$ vetor de efeitos genéticos aditivos maternos, aleatórios;

$\mathrm{e}=$ vetor dos resíduos, aleatórios.

As pressuposições assumidas para esse modelo, em relação aos vetores $\mathrm{y}, \mathrm{a}, \mathrm{m}$, e, são de que possuem distribuição normal com $\mathrm{E}(y)=\mathrm{X} \beta$, $\mathrm{E}(\mathrm{a})=\mathrm{E}(m)=\mathrm{E}(e)=0, \operatorname{Var}(y)=\mathrm{Z}_{1} \mathrm{AZ} \mathrm{Z}^{\prime} \sigma_{\mathrm{a}}^{2}+Z 2$ $Z 2^{\prime}+\mathrm{R}, \operatorname{Var}(\mathrm{a})=\mathrm{A} \sigma_{\mathrm{a}}^{2}, \operatorname{Var}(m)=\mathrm{A} \sigma_{\mathrm{m}}^{2}, \operatorname{Var}(\mathrm{e})=$ $\mathrm{I} \sigma_{\mathrm{e}}^{2}$; sendo: $\mathrm{A}=$ matriz de parentesco, $\mathrm{I}=$ matriz identidade, $\mathrm{R}=$ matriz de variâncias $\mathrm{e}$ covariâncias residuais, $\sigma_{\mathrm{a}}^{2}=$ componente de variância genético aditivo direto, $\sigma_{\mathrm{m}}^{2}=$ componente de variância genético aditivo materno, $\sigma_{\mathrm{e}}^{2}=$ componente de variância residual.

O critério de convergência considerado para as análises com MTDFREML foi de $10^{-6}$, sendo que a cada convergência o programa era reiniciado, usando como valores iniciais aqueles obtidos na análise anterior. A matriz de parentesco estava constituída de 59.824 animais.

Para o estudo da regressão dos valores genéticos para a característica GMDDS, foram utilizados os valores genéticos de cada grupo de animais ponderados pelo número de observações dentro de seu respectivo ano de nascimento, obtidas pelo procedimento PROC REG do pacote estatístico SAS (User's...,1996), utilizando um modelo estatístico do tipo: 
$y_{i}=b_{o}+b_{1} x_{i}+e_{i,}$ em que:

$\mathrm{y}_{\mathrm{i}}=\mathrm{VG}$ para ganho médio diário do desmame ao sobreano do iésimo ano de nascimento;

$\mathrm{b}_{\mathrm{o}}=$ intercepto;

$\mathrm{b}_{1}=$ coeficiente angular da reta;

$\mathrm{x}_{\mathrm{i}}=\mathrm{i}^{\mathrm{e} s i m o}$ ano de nascimento;

$\mathrm{e}_{\mathrm{i}}=$ erro aleatório.

\section{RESULTADOS E DISCUSSÃO}

O número de animais, as médias, os desviospadrão, os coeficientes de variação e os valores mínimos e máximos para a característica GMDDS, por ano de nascimento, são apresentados na Tab. 2. Verifica-se uma tendência de crescimento não muito bem definida no decorrer do período estudado com relação ao número de animais controlados. O menor número foi observado no ano de 1987 , início do programa, e o máximo foi observado no ano de 2001. Os coeficientes de variação (CV) foram altos, ficando, em $80 \%$ dos casos, entre 30 e $40 \%$, evidenciando a grande diferença entre os períodos avaliados, em termos de efeitos ambientais transitórios, e entre os animais nos diferentes rebanhos.

A idade média dos animais na pesagem a desmama variou de 192,7 a 223,8 dias, tendo como média o valor de 212,1 dias. Para a pesagem ao sobreano, a idade variou de 492,3 a 601,8 dias, tendo como média o valor de 540,9 dias.

Tabela 2. Número de animais (N), médias de ganho de peso diário da desmama ao sobreano observadas (GMDDS), desvios-padrão (DP), coeficientes de variação (CV) e valores mínimos e máximos, por ano de nascimento, em uma população multirracial Angus - Nelore

\begin{tabular}{|c|c|c|c|c|c|c|}
\hline Ano & $\mathrm{N}$ & GMDDS (g) & DP (g) & CV (\%) & $\operatorname{Min}(\mathrm{g})$ & $\operatorname{Max}(\mathrm{g})$ \\
\hline 1987 & 235 & 439,81 & 79,59 & 20,00 & 237 & 651 \\
\hline 1988 & 613 & 300,10 & 100,46 & 34,66 & 103 & 775 \\
\hline 1989 & 554 & 364,44 & 102,4 & 28,39 & 128 & 663 \\
\hline 1990 & 1.080 & 344,25 & 119,96 & 37,67 & 120 & 780 \\
\hline 1991 & 1.280 & 371,94 & 135,27 & 36,83 & 122 & 783 \\
\hline 1992 & 2.438 & 299,48 & 102,85 & 35,35 & 120 & 771 \\
\hline 1993 & 2.697 & 314,14 & 105,16 & 34,06 & 122 & 774 \\
\hline 1994 & 1.582 & 361,57 & 110,28 & 30,39 & 123 & 763 \\
\hline 1995 & 4.434 & 347,10 & 111,66 & 32,86 & 121 & 781 \\
\hline 1996 & 2.052 & 397,09 & 114,33 & 28,22 & 124 & 778 \\
\hline 1997 & 1.623 & 441,04 & 132,84 & 31,26 & 147 & 782 \\
\hline 1998 & 2.725 & 426,39 & 125,51 & 30,47 & 120 & 780 \\
\hline 1999 & 2.109 & 484,04 & 134,15 & 30,36 & 120 & 783 \\
\hline 2000 & 3.801 & 459,16 & 135,71 & 30,96 & 121 & 782 \\
\hline 2001 & 6.044 & 412,73 & 134,49 & 33,54 & 120 & 783 \\
\hline Total / Médias & 33.267 & 384,22 & 116,31 & 31,67 & 130 & 762 \\
\hline
\end{tabular}

O GMDDS apresentou tendência de crescimento no decorrer do período estudado, com média observada de $384,22 \mathrm{~g}$ e valores máximos e mínimos entre $783 \mathrm{~g}$ e $103 \mathrm{~g}$, respectivamente. Em 1992 foi observada a menor média $(299,42 \mathrm{~g})$ e em 1999, a maior $(484,04 \mathrm{~g})$.

A estimativa de herdabilidade direta para a característica em estudo foi $0,30 \pm 0,11$, similar à encontrada por Euclides Filho et al. (2000) para animais entre 12 e 18 meses $(0,34 \pm 0,17)$. Todavia, é superior aos valores relatados por Marcondes et al. (2001) e Holanda et al. (2004), os quais obtiveram estimativas de herdabilidade direta para ganho médio diário da desmama ao sobreano de 0,18 e 0,06 , respectivamente, para animais da raça Nelore.

Sarmento et al. (2003), ao trabalharem com rebanhos da raça Nelore, obtiveram estimativas de herdabilidade direta para ganho médio diário dos 365 aos 550 dias de idade de 0,21, indicando que o valor fenotípico pode ser utilizado como estimador satisfatório do valor genético aditivo direto, conseqüentemente, obter ganho genético através da seleção.

Para o GMDDS, o efeito materno também tem grande influência, visto que neste trabalho a herdabilidade materna foi de 0,29 , diferente do 
que foi relatado por Martins Filho et al. (1997) e Garnero et al. (1998), os quais encontraram herdabilidades extremamente baixas para o efeito materno, justificando-as como sendo devidas ao antagonismo entre os efeitos dos genes para potencial de crescimento e de habilidade materna. O valor estimado para a herdabilidade neste trabalho indica que, nessa população, há menor antagonismo entre os efeitos dos genes para potencial de crescimento e de habilidade materna. A correlação entre a herdabilidade direta e materna foi 0,63 , indicando sinergismo entre os efeitos dos genes para potencial de crescimento do bezerro e da habilidade materna da mãe. Resultados diferentes foram relatados por Sarmento et al. (2003), que estimaram valores de $-0,24$ e $-0,44$ para correlação entre herdabilidade de efeito genético direto e materno, para ganho de peso diário da desmama ao ano e ganho de peso diário do ano ao sobreano, respectivamente. Correlação menor e negativa $(-0,22)$ foi obtida por Eler et al. (1996).

$\mathrm{Na}$ Tab. 3 são apresentados os GMDDS e os valores genéticos (VG) médios segundo o ano de nascimento do animal. O valor médio para GMDDS obtido foi de $370,65 \mathrm{~g}$, bem acima do encontrado por Alencar et al. (1998), que estimaram ganho médio diário para animais produto do cruzamento entre as raças Canchim e Nelore de $0,319 \mathrm{~kg}$ entre o desmame e os 18 meses de idade.

O VG anual médio estimado para GMDDS foi de $-0,827 \mathrm{~g}$. O ano de 1991 apresentou o maior valor e o de 1996, o menor. O comportamento oscilatório para o VG anual médio e a diferença superior a $600 \mathrm{~g}$ entre o $\mathrm{VG}$ mais positivo e o mais negativo evidenciam a diversidade genética da população estudada e sugerem não estar havendo um programa de seleção bem estruturado tendo como objetivo o melhoramento dessa característica.

A tendência genética anual foi de $-0,029 \mathrm{~g} /$ ano $\left(\mathrm{P}<0,08 ; \mathrm{r}^{2}=0,42\right)$, valor próximo de zero (Fig. 1). Euclides Filho et al. (2000), ao trabalharem com a raça Gir, observaram como resultado da regressão das diferenças esperadas na progênie (DEP) um ganho de peso médio diário pósdesmama de $0,026 \mathrm{~g}$, valor inferior aos relatados por Silva et al. (1997) e Holanda et al. (2004), os quais encontraram tendência genética direta para ganho de peso pós-desmama de 109,0 e $75,20 \mathrm{~g} / \mathrm{ano}$, para a raça Nelore. Segundo Smith (1985), a taxa de mudança genética anual possível de ser obtida varia de um a três por cento da média da população, valores esses bastante superiores ao encontrado neste trabalho.

Tabela 3. Ganho médio diário da desmama ao sobreano (GMDDS) e valores genéticos (VG) médios, por ano de nascimento, em uma população multirracial Angus-Nelore

\begin{tabular}{ccc}
\hline Ano & GMDDS $(\mathrm{g})$ & $\mathrm{VG}(\mathrm{g})$ \\
\hline 1987 & 411,702 & $-136,553$ \\
1988 & 300,965 & 190,044 \\
1989 & 372,305 & 0,027 \\
1990 & 326,328 & $-153,255$ \\
1991 & 373,818 & 204,935 \\
1992 & 289,429 & $-200,640$ \\
1993 & 305,378 & $-427,740$ \\
1994 & 367,359 & $-0,078$ \\
1995 & 324,354 & $-0,643$ \\
1996 & 406,342 & $-466,348$ \\
1997 & 429,054 & $-0,769$ \\
1998 & 408,344 & $-131,799$ \\
1999 & 442,686 & 0,532 \\
2000 & 427,334 & $-219,642$ \\
2001 & 374,353 & 193,529 \\
\hline
\end{tabular}

Tendências genéticas próximas de zero e até mesmo negativas, segundo Euclides Filho et al. (1997b), não são incomuns na literatura, principalmente quando resultam de avaliações realizadas com dados provenientes de rebanhos comerciais, cujos critérios de seleção não são bem definidos e, principalmente, não são uniformes.

A reta de tendência fenotípica (Fig. 2), de 5,69g $\left(\mathrm{P}<0,05 ; \mathrm{r}^{2}=0,25\right)$, indica estar havendo pequeno progresso fenotípico na população avaliada.

Resultados que indiquem pequeno progresso fenotípico não são raros, principalmente quando estimados para rebanhos criados em ambientes distintos, submetidos aos mais diversos sistemas de produção, como é o caso do gado de corte no Brasil, conforme relatado por Silva et al. (1997), Euclides Filho et al. (1997a), Euclides Filho et al. (1997b) e Euclides Filho et al. (2000), respectivamente, para as raças Nelore, Indubrasil, Guzerá e Gir. 


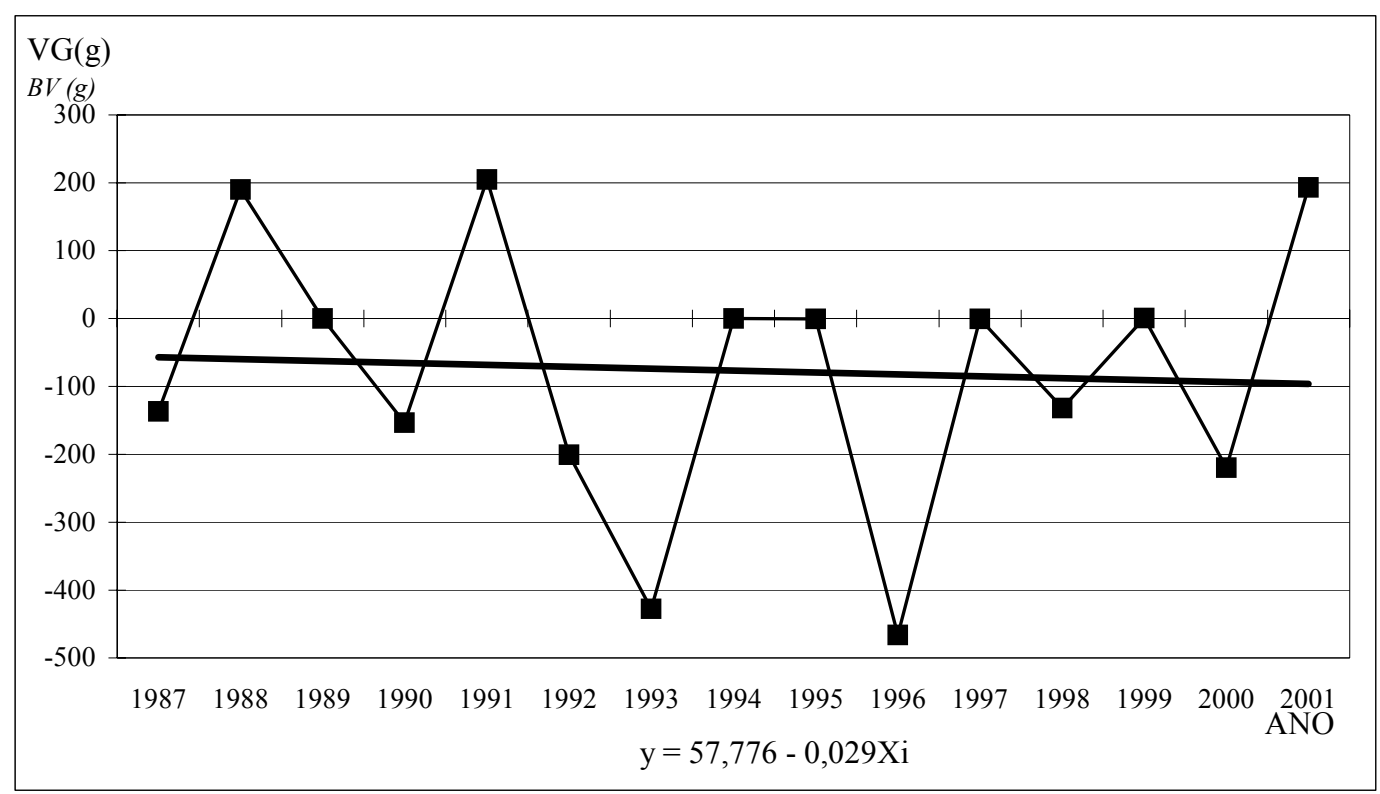

Figura 1. Valores genéticos (VG) médios anuais (g), com reta de tendência genética, para o ganho de peso médio diário da desmama ao sobreano, para população Angus-Nelore

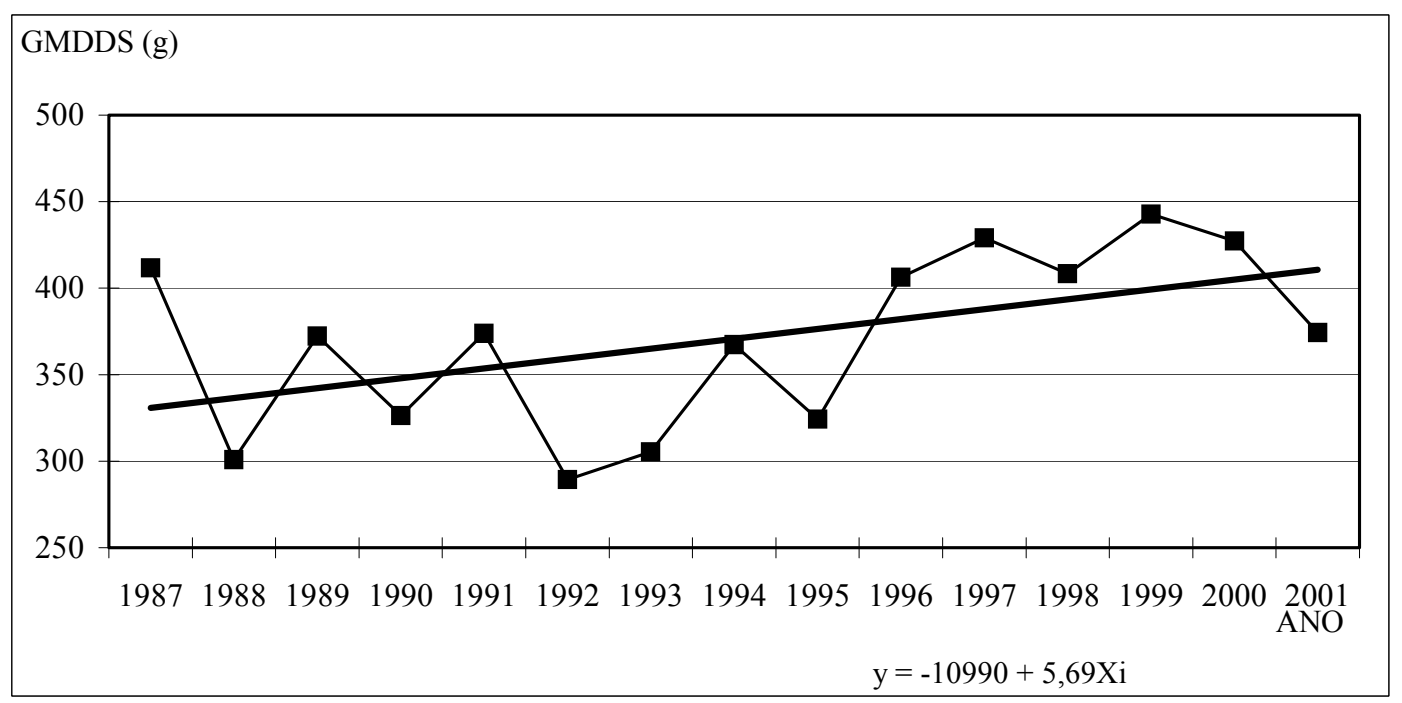

Figura 2. Médias anuais (g), com reta de tendência fenotípica, para o ganho de peso médio diário da desmama ao sobreano (GMDDS), para uma população multirracial Angus - Nelore

Os resultados deste trabalho indicam que, embora os produtores estejam conseguindo progresso anual no desempenho de seus animais, esse resultado é devido quase que totalmente à melhoria nas condições de ambiente a que os animais estão sendo submetidos, pois a contribuição da fração genética não está sendo significativa. Assim, se não houver melhoria genética no rebanho, o retorno devido à evolução ambiental tende a atingir seu limite.

\section{CONCLUSÕES}

O coeficiente de herdabilidade direta para GMDDS sugere haver a possibilidade de se obter 
ganho genético por meio da seleção. A correlação alta e positiva entre essa e a herdabilidade materna sugere a possibilidade de se obter progresso genético para as duas características. A tendência genética próxima de zero evidencia a necessidade do uso de programas de melhoramento genético que apontem touros de maior VG para ganho de peso, o que possibilitaria maior e melhor desempenho dos animais nas condições a que estão submetidos. A tendência fenotípica crescente sugere que, mesmo sem progresso genético, pode ocorrer progresso fenotípico, entretanto, se não forem adotadas medidas seletivas, com o objetivo de incrementar o ganho genético, chegará o momento em que o progresso fenotípico tenderá a se estabilizar.

\section{AGRADECIMENTOS}

A Gensys Consultores Associados e Natura Genética Sul-Americana, pelo fornecimento dos dados.

\section{REFERÊNCIAS BIBLIOGRÁFICAS}

ALENCAR, M.M.; BARBOSA, P.F.; TULLIO, R.R. et al. Estimativas de efeitos aditivos e heteróticos para peso à desmama de bezerros cruzados Canchim x Nelore e Marchigiana x Nelore. Rev. Bras. Zootec., v.24, p.917-925, 1995.

ALENCAR, M.M.; OLIVEIRA, M.C.S.; BARBOSA, P.F. et al. Pesos e ganhos de peso de bovinos cruzados Canchim $\mathrm{x}$ Nelore. In: REUNIÃO ANUAL DA SOCIEDADE BRASILEIRA DE ZOOTECNIA, 35., 1998, São Paulo. Anais... São Paulo: SBZ/Gnosis, 1998, 17 par. CD-ROM. Melhoramento Animal. MEL077.

BOLDMAN, K.H.; KREISE, L.A.; VAN VLECK, L.D. et al. A manual of MTDFREML: a set of programs to obtain estimates of variances and covariance (DRAFT). Lincoln: Agricultural Research Service, 2001. 114p.

ELER, J.P.; FERRAZ, J.B.S.; SILVA, P.R. Parâmetros genéticos para peso, avaliação visual e circunferência escrotal na raça Nelore, estimado por modelo animal. Arq. Bras. Med. Vet. Zootec., v.48, p.203-213, 1996.
EUCLIDES FILHO, K.; SILVA, L.O.C.; ALVES, R.G.O. et al. Tendências genéticas na raça Indubrasil. In: REUNIÃO ANUAL DA SOCIEDADE BRASILEIRA DE ZOOTECNIA, 34., 1997, Juiz de Fora. Anais... Juiz de Fora: SBZ, 1997a. p.171.

EUCLIDES FILHO, K.; SILVA, L.O.C.; FIGUEIREDO, G.R. Tendências genéticas na raça Guzerá. In: REUNIÃO ANUAL DA SOCIEDADE BRASILEIRA DE ZOOTECNIA, 34., 1997, Juiz de Fora. Anais... Juiz de Fora: SBZ, 1997b. p.173.

EUCLIDES FILHO, K.; SILVA, L.O.C.; ALVES, R.G.O. et al. Tendência genética da raça Gir. Pesq. Agrop. Bras., v.35, p.787-791, 2000.

FALCONER, D.S.; MACKAY, T.F.C. Introduction to quantitative genetics. Essex: Longman, 1996. 464p.

FERNANDES, H.D.; FERREIRA, G.B.; RORATO, P.N.R. Tendências e parâmetros genéticos para características de crescimento em bovinos Charolês criados no Rio Grande do Sul. Rev. Bras. Zootec., v.31, p.321-330, 2002.

GARNERO, A.V.; LÔBO, R.B.; BORJAS, A.R. et al. Estimativas de parâmetros genéticos para características incluídas em critérios de seleção em gado de corte. In: REUNIÃO ANUAL DA SOCIEDADE BRASILEIRA DE ZOOTECNIA, 35., 1998, Botucatu. Anais... Botucatu, SBZ, 1998. p.424-456.

HILL, W.G. Design of quantitative genetics selection experiments. In: ROBERTSON, A. (Ed.) Selection experiments in laboratory and domestic animals. Slough: CAB, 1980. p.1-13.

HOLANDA, M.C.R.; BARBOSA, S.B.P.; RIBEIRO, A.C. et al. Tendências genéticas para crescimento em bovinos Nelore em Pernambuco, Brasil. Arch. Zootec. v.53, p.185-194, 2004.

MARCONDES, C.R.; BERGMANN, J.A.G.; ELER, J.P. et al. Análises de alguns critérios de seleção para características de crescimento na raça Nelore. Arq. Bras. Med. Vet. Zootec., v.52, p.83-89, 2000.

MARTINS FILHO, R.; LÔBO, R.N.B.; LIMA, F.A.M. et al. Parâmetros genéticos e fenotípicos de pesos e ganhos em pesos de bovinos zebus no estado do Ceará. In: REUNIÃO ANUAL DA SOCIEDADE BRASILEIRA DE ZOOTECNIA, 
34., 1997, Juiz de Fora, MG. Anais... Juiz de Fora, SBZ, 1997. p.248-250.

MELLO, S.P. Tendência genética para pesos em um rebanho da raça Canchim. 1999. Dissertação (Mestrado em Zootecnia) - Faculdade de Ciências Agrárias e Veterinárias, Universidade Estadual Paulista, Jaboticabal, SP.

OLIVEIRA, J.A.; LÔBO, R.B.; OLIVEIRA, H.N. Tendência genética em pesos e ganhos em peso de bovinos da raça Guzerá. Pesq. Agrop. Bras., v.30, p.1355-1360, 1995.

PACKER, I.U. Análise genética do crescimento até a desmama de bezerros Canchim. 1977. 173f. Tese (Livre Docência) - Escola Superior de Agricultura Luiz de Queiroz, Universidade Federal de São Paulo, Piracicaba, SP.

SILVA, L.O.C.; EUCLIDES FILHO, K.; NOBRE, P.R.C. et al. Tendência genética na raça Nelore no Brasil. In: REUNIÃO ANUAL DA SOCIEDADE BRASILEIRA DE ZOOTECNIA, 34., 1997, Juiz de Fora. Anais... Juiz de Fora: SBZ, 1997. p.175.

SARMENTO, J.L.R.; PIMENTA FILHO, E.C.; RIBEIRO, M.N. et al. Efeitos ambientais e genéticos sobre o ganho em peso médio diário de bovinos Nelore no estado da Paraíba. Rev. Bras. Zootec., v.32, p.325-330, 2003.

SMITH, C. Rates of genetic change in farm livestock. Res. Develop. Agric., v.1, p.79-85. Anim. Breed. Abst., v.53, p.699, 1985.

SORENSEN, D.A.; KENNEDY, B.W. Estimation of response to selection using lastsquares and mixed model methodology. J. Anim. Sci., v.58, p.1097-1106, 1984.

SORENSEN, D.A.; KENNEDY, B.W. Analysis of selection experiments using mixed model methodology. J. Anim. Sci., v.63, p.245-258, 1986.

SOUZA, J.C.; RAMOS,A.A.; SILVA, L.O.C. et al. Tendência genética do peso ao desmame de bezerros da raça Nelore. In: REUNIÃO ANUAL DA SOCIEDADE BRASILEIRA DE ZOOTECNIA, 35., 1998, Botucatu. Anais... Juiz de Fora: SBZ, 1998. p.231

USER'S guide: statistical analysis systems. Version 6.11. Cary, NC: SAS Institute, 1996.

WALSH, J.B. Mixed-model and bayesian analysis of short-term selection experiments. Disponível em:

$<$ http://biosci.arizona.edu/zbook/volume2/chapte rs/vol12 > . Acessado em: 21/out./2003. 